\title{
Cripto-1 promotes epithelial-mesenchymal transition in prostate cancer via Wnt/ $\beta$-catenin signaling
}

\author{
YAN LIU ${ }^{1}$, ZHENBANG QIN $^{1}, \mathrm{KUO} \mathrm{YANG}^{1}, \mathrm{RANLU}^{\mathrm{LIU}}{ }^{1,2}$ and YONG XU${ }^{1,2}$ \\ ${ }^{1}$ Prostate Disease Laboratory, Tianjin Institute of Urology, Tianjin 300211; \\ ${ }^{2}$ Department of Urology, The Second Hospital of Tianjin Medical University, Tianjin 300211, P.R. China
}

Received August 1, 2016; Accepted December 21, 2016

DOI: 10.3892/or.2017.5378

\begin{abstract}
The Cripto-1 (CR-1) derived EGF-CFC family was overexpressed in tumor development enhancing proliferation, epithelial-mesenchymal transition (EMT) and migration of tumor cells. However, correlation between CR-1 and prostate cancer $(\mathrm{PCa})$ remains still unclear. In the present study, we proved that $\mathrm{CR}-1$ was expressed in $\mathrm{PCa}$ and its function was in the progression of $\mathrm{PCa}$. Compared with benign prostatic hyperplasia (BPH) tissues, we confirmed that $\mathrm{PCa}$ tissues had high expression of CR-1 by immunohistochemistry and statistical data showed that CR-1 promoted properties of EMT in PCa tissues, including the downregulation of the cell adhesion molecules $\beta$-catenin (membrane) and E-cadherin while upregulating transcription factors $\beta$-catenin. Overexpression of CR-1 had close relationship with PSA, Gleason, clinical staging and lymph node metastasis in PCa patients. Then, we found that PC-3 cells transfected with CR-1-shRNA inhibited EMT using RT-PCR, RT-qPCR, western blotting and immunofluorescence. Also, we evaluated cell invasive ability in vitro by Transwell and wound-healing assay. Our data showed that transfected CR-1-shRNA altered EMT including $\beta$-catenin, E-cadherin, c-myc, GSK-3, p-GSK and Wnt/ $\beta$-catenin pathway in PC-3. It also suppressed PC-3 cell migration. Additionally, our results displayed that Licl had antitumor activity against PC-3 through the inhibition of $\mathrm{Wnt} / \beta$-catenin pathway. Inhibition of cell viability was dose-time dependent. The present study proved that $\mathrm{CR}-1$ regulates EMT of $\mathrm{PCa}$ by $\mathrm{Wnt} / \beta$-catenin pathway. Hence, $\mathrm{CR}-1$ may provide a new biological marker, and possibly contributes to clinical treatment against $\mathrm{PCa}$.
\end{abstract}

Correspondence to: Professor Yong $\mathrm{Xu}$, Department of Urology, The Second Hospital of Tianjin Medical University, 23 Pingjiang Road, Hexi, Tianjin 300211, P.R. China

E-mail: xuyong8816@sina.com

Key words: cripto-1, epithelial-mesenchymal transition, prostate cancer, Wnt $/ \beta$-catenin, signaling pathway

\section{Introduction}

Prostate cancer (PCa) is generally diagnosed with malignant tumor and this is important in terms of mortality. Approxiamtely 180,890 new cases are estimated for 2016 and more than 26,120 PCa deaths will occur in the USA. PCa has exceeded lung cancer in men accounting for $21 \%$ of all male malignancies. PCa is also the second cause of death in men (1). Its incidence rates vary between countries. Incidence rate of PCa in Asia is widely accepted to be the lowest all over the world. However, it has gradually increased recently (2). Aside from age and race, the risk factor for $\mathrm{PCa}$ is a family history of the disease. In addition, its greater prevalence in the west implicates lifestyle and environmental risk factors (3). Currently, there is no reliable prediction methods and effective clinical therapies for PCa. However, similar to other human malignancies, clinical relevance of genetics and molecular mechanism supporting PCa development and progression remain poorly understood.

CR-1 is an EGF-CFC family member gene (4). CR-1 was primitively found from NTERA2 (5). The anchor protein CR-1 contains extracellular signal sequence, EGF-like domain and CFC-motif, GPI attachment. CR-1 takes actively part in the mediation of the embryonic development and malignant tumor occurrence (6). CR-1 is an obligatory co-receptor during embryogenesis (7). CR-1 is expressed at low level in adults. In contrast, high levels of CR-1 are detected in many cancer patients (8). CR-1 plays important roles in promoting tumor cell progression, stimulating cell proliferation and invasion between epithelial-mesenchymal transition (EMT) $(9,10)$.

Previous research has reported that different kinds of cells in the embryonic development and progression of malignant tumor share common signaling pathways. The study of Wechselberger et al (11) revealed that CR-1 might be a mediator of the effects of activated $\mathrm{Wnt} / \beta$-catenin pathway in hyperplasia and adenocarcinoma of mouse mammary gland $(12,13)$. Epithelial-mesenchymal transition (EMT) can promote attached epithelial cells into individual migration into the extracellular matrix (14). Prasad et al (15) reported that Wnt/ $\beta$-catenin signaling upregulated invasion of breast cancer cells. It contained E-cadherin and GSK3 $\beta$ in implementing EMT. Wnt/ $\beta$-catenin pathway contributed to epithelial tissue inducing EMT to produce signal transduction pathways. Thus, 
Table I. Primer for RT-PCR and RT-qPCR.

\begin{tabular}{llll}
\hline Gene & \multicolumn{1}{c}{ Forward primer } & \multicolumn{1}{c}{ Reverse primer } & Product (bp) \\
\hline CR-1 & 5'-GGAATTTGCTCGTCCATCTC-3' & 5'-ACCGTGCCAGCATTTACAC-3' & 307 \\
$\beta$-catenin & 5'-GCAACCAAGAAAGCAAGCTC-3' & 5'-GCTGAACAAGAGTCCCAAGG-3' & 303 \\
E-cadherin & 5'-AAACAGGATGGCTGAAGGTG-3' & 5'-TCTTGGCTGAGGATGGTGTA-3' & 295 \\
c-myc & 5'-CCGAGGAGAATGTCAAGAGG-3' & 5'-ACGCACAAGAGTTCCGTAGC-3' & 270 \\
$\beta$-actin & 5'-CTCTTCCAGCCTTCCTTCCT-3' & 5'-ACTCCTGCTTGCTGATCCAC-3' & 304 \\
\hline
\end{tabular}

we hypothesized that CR-1 would promote PCa occurrence by the $\mathrm{Wnt} / \beta$-catenin pathway.

Now, we describe connection of CR-1 and EMT with PCa tissues. We found an important role of CR-1 in PCa cells by the Wnt/ $\beta$-catenin pathway. Furthermore, CR-1 positively regulated invasion, migration and EMT. These results shed light on the mechanisms by which PCa occurs, develops and provides evidence for CR-1 as a new biological marker contributing to clinical treatment against PCa.

\section{Materials and methods}

Human prostate specimens. The present study on human prostate specimens was approved by the Ethics Committee of the Second Hospital of Tianjin Medical University. Specimens were obtained from patients with signed informed consent for use in research. Patient tissues were collected immediately and then were quickly frozen with liquid nitrogen. Patients did not receive therapy before surgery. Prostate cancer tissues were collected after radical prostatectomy at the Department of Urology of the hospital. Adjacent normal tissues were gained from the same patients. Hematoxylin and eosin (H\&E) staining sections were used to identify the tissues by pathologists.

Cell culture. LNCap, PC-3 and RWPE-1 were maintained in our laboratory. LNCap and PC-3 were cultivated in RPMI1640 medium (Gibco, Shanghai, China) with $10 \%$ fetal bovine serum (FBS). RWPE-1 was incubated in keratinocyte serumfree medium (K-SFM; Gibco). All the cells were incubated at $37^{\circ} \mathrm{C}$ and $5 \% \mathrm{CO}_{2}$.

Plasmid construction and cell transfection. According to the shRNA design principle, four suitable shRNA target sequences (sh1-4), from human CR-1 gene GenBank accession no. NM_001174136.1, were synthesized, respectively: sh-1, CCA TCAGGAATTTGCTCGTCC; sh-2, GCAAATTTCATGAC CAGTAAA; sh-3, CCTAACTGAAAGATGATCATT; and sh-4 CCAAGGTCTTCTTAATATGTT. A small hairpin RNA (shRNA) of CR-1 exists in psi-U6.1 vector. GeneCopoeia constructed plasmids with enhanced green fluorescent protein (EGFP) and puromycin resistance (cat. no. HSH060851-CU6; GeneCopoeia, Guangzhou, China). We transfected the plasmid when PC-3 cells were 90\% confluent. Lipofectamine 2000 (Invitrogen) was in strict accordance with the instructions of the manufacturer. Fluorescence microscopy was used to observe the transfection efficiency.
Immunohistochemical (IHC) staining. Sixty PCa and $60 \mathrm{BPH}$ tissues were collected from the Urology Department. Xylene was used to deparaffinize and hydrate paraffin-embedded sections $(4 \mu \mathrm{m})$ followed by graded alcohols to water; $0.01 \mathrm{M}$ citrate for $10 \mathrm{~min}$ was used for antigen retrieval. Then slowly cooled down. Primary antibodies, horseradish peroxidase and DAB were then used, respectively (Beijing Zhongshan Golden Bridge, Beijing, China). Finally, sections were counterstained and dehydrated. Antibodies were as follows: anti-CR-1 (Sigma-Aldrich) anti- $\beta$-catenin and anti-E-cadherin (Beijing Zhongshan Golden Bridge).

Immunofluorescence (IF). For detection of CR-1, E-cadherin and $\beta$-catenin cells were put on the coverslips. Paraformaldehyde (4\%), $0.1 \%$ Triton X-100, primary antibodies and secondary antibodies were then used. The secondary antibodies were labeled by conjugation for $90 \mathrm{~min}$ at RT in the dark. After washing, DAPI stained cells for $5 \mathrm{~min}$. After extensive washing, cells were mounted on glass slides with antifade solution and the fluorescence was visualized by laser scanning confocal microscopy using a 200x lens (FV1000; Olympus Optical, Co., Ltd., Tokyo, Japan).

MTT assay (3-(4,5-dimethylthiazol-2-yl)-2,5-diphenyltetrazolium bromide). PC-3 was placed with $1 \times 10^{4}$ cells/well. Lithium chlorides (Licl) have different concentrations at various time intervals $(12,24$ and 48 h). Next, each well was added with MTT solution. Then, each well was put into dimethyl sulfoxide (DMSO) and rotated at room temperature (RT). The absorbance value was measured with microplate reader at $570 \mathrm{~nm}$ (BioTek Instruments, Inc., Winooski, VT, USA).

$R T$ - $q P C R$ and $R T$-PCR assay. EasyPure ${ }^{\circledR}$ kit (TransGen Biotech, Inc., Beijing, China) was applied to extract total RNA. We applied TransScript ${ }^{\circledR}$ SuperMix (TransGen Biotech) to synthesis of cDNA. RT-qPCR was used with SYBR-Green Master Mix kit (Roche, Basel, Switzerland) and GADPH was used as the internal reference. Samples were denaturized at $95^{\circ} \mathrm{C}$ for $10 \mathrm{~min}$, followed by 45 cycles at $95^{\circ} \mathrm{C}$ for $15 \mathrm{sec}, 60^{\circ} \mathrm{C}$ for $30 \mathrm{sec}$ and $72^{\circ} \mathrm{C}$ for $15 \mathrm{sec}$. cDNA template was amplified with 2X EasyTaq ${ }^{\circledR}$ PCR Mix (TransGen Biotech) for RT-PCR. Reaction conditions were $94^{\circ} \mathrm{C}$ for $5 \mathrm{~min}, 35$ cycles of: $94^{\circ} \mathrm{C}$ for $30 \mathrm{sec}, 60^{\circ} \mathrm{C}$ for $30 \mathrm{sec}$ and $72^{\circ} \mathrm{C}$ for $60 \mathrm{sec}$ and $72^{\circ} \mathrm{C}$ for $10 \mathrm{~min}$. Then, samples were electrophoresed with $2.5 \%$ agarose gel. The primers (Sangon Biotech Co., Ltd., Shanghai, China) were designed as showen in Table I. Each sample was run in triplicate. 


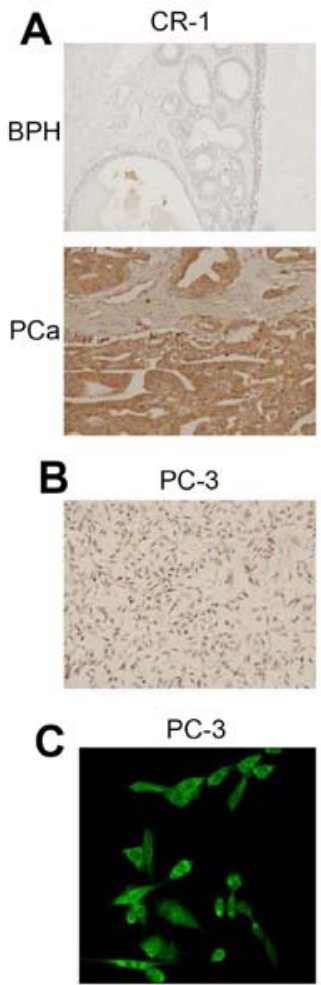

RWPE-1

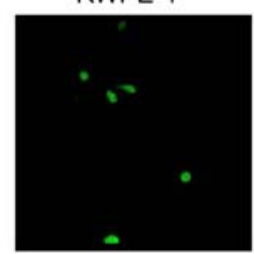

$\beta$-catenin
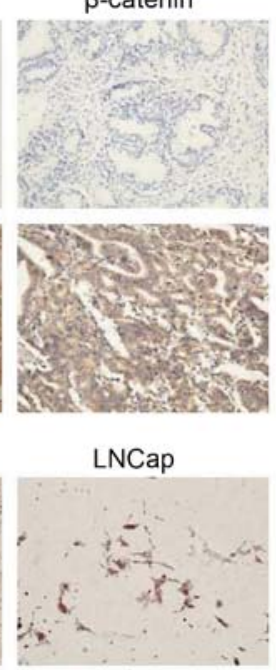

DAPI

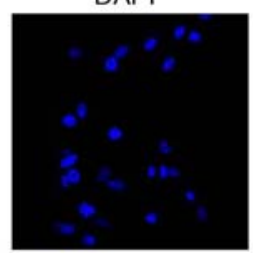

DAPI

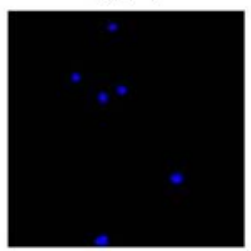

E-CD (x200)
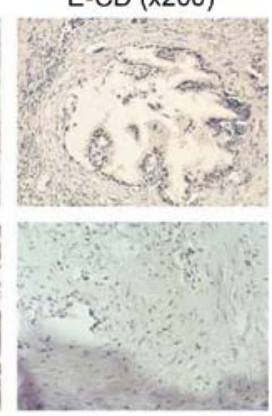

RWPE-1 (x100)

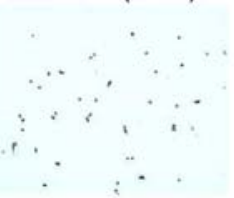

Merge $(x 400)$

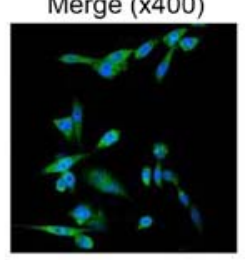

Merge (x400)

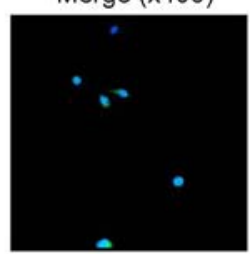

Figure 1. Correlation between CR-1 expression and EMT in PCa specimens (A) Immunohistochemical CR-1, E-CD and $\beta$-catenin protein expression in $\mathrm{BPH}$ and PCa tissues (magnification, $\mathrm{x} 200$ ). (B) Immunohistochemical CR-1 protein expression in PC-3 cells, LNCap cells and RWPE-1 cells (magnification, x100). Brown granules in the cytoplasm are CR-1 protein. (C) No or weak expression of CR in RWPE-1, strong cytoplasm and cell nucleus expression of CR-1 in the majority of PC-3 (magnification, x200).

Western blotting. For analyzing the expression of related proteins, standard methods were performed as previously described (16). $\beta$-catenin, E-cadherin, c-myc, GSK-3 $\beta$ and p-GSK-3 $\beta$ (1:500; Bioworld Technology, Inc., St. Louis Park, MN, USA) were used for the primary antibody; GADPH was used as loading control (1:1,000; Bioworld Technology).

Wound healing test. PC-3 was incubated up to $90 \%$ confluence and transfected in 6-well plates. After $48 \mathrm{~h}$, cells were scraped with a pipette tip. Then, the cells were further incubated for 12 and $24 \mathrm{~h}$. Wounded regions were photographed at x40 amplification using computer-aided microscopy (Nikon Eclipse Ti-U; Nikon, Tokyo, Japan). Captured image were obtained 0, 12 and $24 \mathrm{~h}$ after the wounding. The distance the cells migrated was measured and analyzed using FV10-ASW 4.0 Viewer cell image analysis software (Olympus).

Transwell invasion assay. Assay was implemented using Transwell inserts (Corning, Inc., Corning, NY, USA) with Matrigel matrixes (BD Biosciences, San Jose, CA, USA) in
Table II. Expression correlations between CR-1, E-cadherin and $\beta$-catenin in PCa tissues for IHC.

\begin{tabular}{llllll}
\hline & & \multicolumn{3}{c}{ CR-1*E-cadherin/ $\beta$-catenin } \\
\cline { 3 - 6 } & & \multicolumn{2}{c}{ E-cadherin } & & $\beta$-catenin \\
\cline { 3 - 6 } & & & + & & + \\
\hline CR-1 & & & & & \\
- & Count & 20 & 5 & 9 & 16 \\
& \% of total & 33 & 8 & 15 & 27 \\
& Count & 16 & 19 & 4 & 31 \\
\multirow{2}{*}{ Total } & \% of total & 27 & 32 & 6 & 52 \\
& Count & 36 & 24 & 13 & 47 \\
& \% of total & 60 & 40 & 21 & 79
\end{tabular}

Statistical analyses were performed using the Chi-square test and the McNemar's statistical test.

24-well plates. A total of $1 \times 10^{5} / \mathrm{ml}$ transfected PC-3 cells were added into the apical chamber and RPMI-1640 was added into basolateral chamber. Cells were then cultured for $24 \mathrm{~h}$. Inserts were scraped with cotton swabs and fixed in paraformaldehyde. In addition, then they were added with crystal violet. The PC-3 cells on permeable membrane were distinguished using microscope with a camera.

Statistical analysis. We used the GraphPad Prism 5.0 and the SPSS 16.0. We established the statistically significant difference making use of two-tailed Student's t-test, Chi-square test and McNemar's statistical test. $\mathrm{P}<0.05$ and $\mathrm{P}<0.01$ were deemed statistically significant.

\section{Results}

CR-1 is highly expressed and correlated with EMT in PCa tissues. We elected $60 \mathrm{PCa}$ and $60 \mathrm{BPH}$ patient tissues for immunohistochemistry. In BPH tissues, CR-1 expression was low at levels; however, CR-1 expression was high in PCa tissues. Thus, CR-1 was overexpressed in PCa tissues (Fig. 1A). CR-1 expression in PC-3 cells was the highest of all the cells (Fig. 1B). In our studies, immunohistochemistry staining showed that CR-1 was predominantly localized to the cytoplasm of PCa cells. Immunofluorescence (IF) showed that CR-1 protein was expressed both in the nucleus and cytoplasm, but mainly in the cytoplasm (Fig. 1C). CR-1 levels positively correlated with $\beta$-catenin in the cytoplasm $(\mathrm{P}<0.05)$. CR-1 levels were contrary to the E-CD levels $(\mathrm{P}<0.05)$ (Table II). Table III shows the relationship between the CR-1 expression and the clinicopathological parameters. Expression of CR-1 has no correlation with age; however, overexpression of CR-1 and PSA ( $<4$ vs. $4-10$ vs. $>10 \mathrm{ng} / \mathrm{ml}$; $\mathrm{P}<0.01$ ), Gleason ( $\leq 7$ vs. $>7$; $\mathrm{P}<0.05$ ), clinical staging (I-II vs. III-IV; $\mathrm{P}<0.05$ ) and lymph node metastasis (no vs. positive; $\mathrm{P}<0.05$ ) had close relationships. We suggest that $\mathrm{CR}-1$ was closely linked with PCa progression and relative EMT marker protein. 
Table III. Clinicopathological data of Cripto-1 in PCa.

\begin{tabular}{|c|c|c|c|c|}
\hline Clinical data & $\mathrm{N}$ & CR-1- $(\%)$ & $\mathrm{CR}-1+(\%)$ & P-value \\
\hline \multicolumn{5}{|c|}{ Age at registration (years) } \\
\hline$\geq 70$ & 25 & $10(40.00)$ & $15(60.00)$ & \multirow[t]{2}{*}{0.825} \\
\hline$<70$ & 35 & $15(42.86)$ & $20(57.14)$ & \\
\hline \multicolumn{5}{|c|}{ Serum PSA (ng/ml) } \\
\hline$<4$ & 2 & $1(50.00)$ & $1(50.00)$ & \multirow{3}{*}{$0.007^{\mathrm{a}}$} \\
\hline $4-10$ & 9 & $8(88.89)$ & $1(11.11)$ & \\
\hline$>10$ & 49 & $16(32.65)$ & $33(67.35)$ & \\
\hline \multicolumn{5}{|l|}{ Gleason score } \\
\hline$<7$ & 9 & $4(44.44)$ & $5(55.56)$ & \multirow[t]{3}{*}{$0.032^{\mathrm{b}}$} \\
\hline 7 & 18 & $3(16.67)$ & $15(83.33)$ & \\
\hline$>7$ & 33 & $18(54.55)$ & $15(45.45)$ & \\
\hline \multicolumn{5}{|l|}{ Clinical stage } \\
\hline I-II & 27 & $16(59.26)$ & $11(40.74)$ & \multirow[t]{2}{*}{$0.012^{\mathrm{b}}$} \\
\hline III-IV & 33 & $9(27.27)$ & $24(72.73)$ & \\
\hline \multicolumn{5}{|c|}{ Lymph node metastasis } \\
\hline No & 15 & $10(66.67)$ & $5(33.33)$ & \multirow[t]{2}{*}{$0.023^{\mathrm{b}}$} \\
\hline Yes & 45 & $15(33.33)$ & $30(66.67)$ & \\
\hline
\end{tabular}

Statistical analyses were performed using the Chi-square test. ${ }^{a} \mathrm{P}<0.01,{ }^{b} \mathrm{P}<0.05$.

A

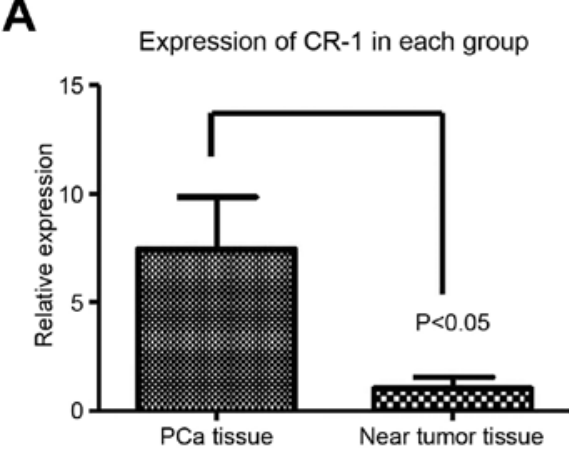

C

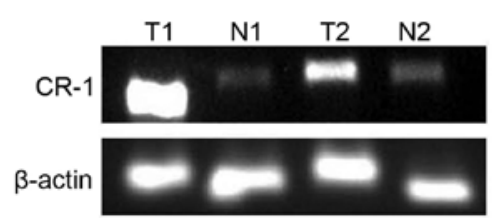

B

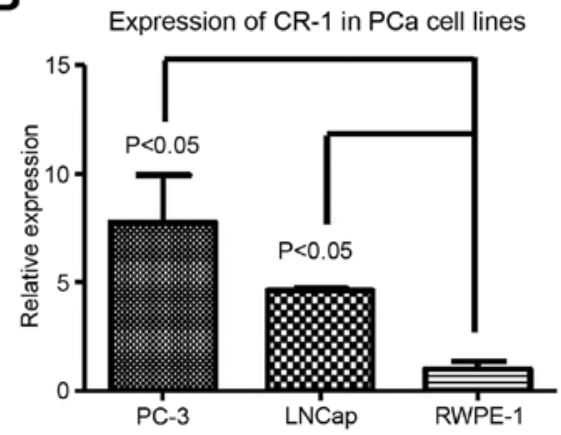

D

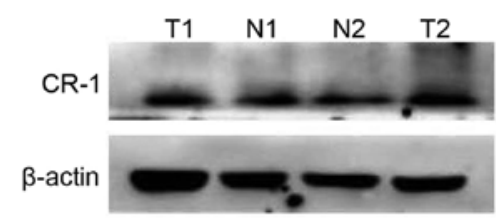

Figure 2. CR-1 gene is expressed in prostate tissues and cells. (A) Expression of CR-1 in PCa tissues and near tumor tissues was assessed by RT-qPCR (P $<0.05$ ). (B) CR-1 in PCa cell lines were verified using RT-qPCR $(\mathrm{P}<0.05)$. Levels near tumor tissues and in RWPE-1 were regarded as $100 \%$ (A and B), and PCa tissues were compared with near tumor tissues, and RWPE-1 was compared with PC-3 and LNCap. (C) CR-1 in PCa and near tumor tissues was detected by RT-PCR. PCR results were analyzed. (D) CR-1 in PCa and near tumor tissues was verified using western blotting.

Expression of $m R N A$ and protein in prostate cells and tissues. We used RT-PCR, RT-qPCR and western blot technology to detect CR-1 in prostate cells and tissues. CR-1 level was shown in the prostate specimens (PCa tissues, $n=10$; near tumor tissues, $n=10$ ) using RT-PCR and RT-qPCR (Fig. 2A and C). In comparison with the near tumor tissues, upregulated CR-1 $(\mathrm{P}=0.0187)$ was displayed in PCa tissues (Fig. 2A, C and D).
Expression of CR-1 was higher in PC-3 cells (Fig. 2B). Thus, we used the PC-3 cell line for the next experiment in PCa.

Expression of EMT relative protein after CR-1 shRNA transfection in PC-3. After PC-3 cell transfection with shRNA, CR-1 expression was downregulated. Expression of the CR-1-shRNA plasmid vector (NC/CR-1-shRNA1-4) decreased red fluorescent 


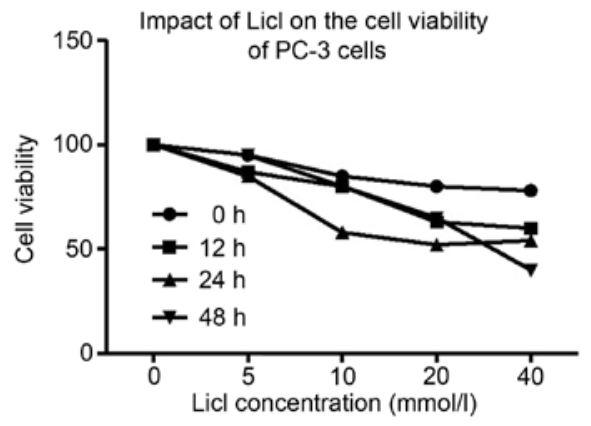

Figure 3. Impact of Licl consists in the cell viability of PC-3 cells. Cells $\left(1 \times 10^{4}\right.$ cells/well) were measured on $0,12,24$ and $48 \mathrm{~h}$ after the mixture with different concentrations of Licl.
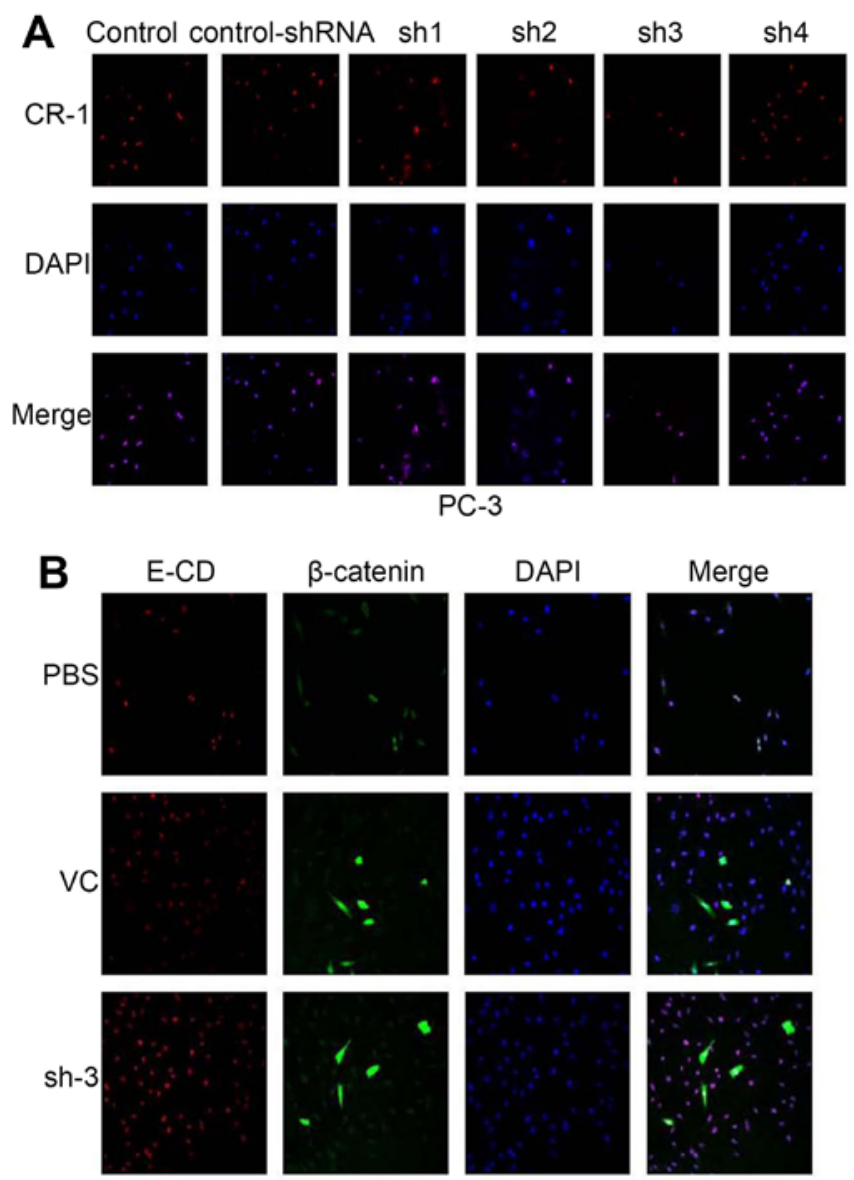

PC-3

Figure 4. (A) CR-1 shRNA plasmid (CR-1-shRNA1-4) constuction and PC-3 cell transfection (magnification, x200). (B) Wnt/ $\beta$-catenin signaling pathway marker $\beta$-catenin (green) and epithelial marker E-cadherin (red) were visualized by immunofluorescence following staining for nucleus with DAPI (blue) in PC-3 cells transfected with PBS, vector control and CR-1-shRNA-3 (magnification, x200).

protein (RFP) was evaluated using scanning confocal microscopy in PC-3. We counted transfection efficiency under a fluorescent microscope for $48 \mathrm{~h}$ after transfection. CR-1shRNA-3 had the most preferable interference effect (Fig. 4A). CR-1-shRNA-3 was selected for the next experiments. $\beta$-catenin (a Wnt signaling pathways marker) and E-cadherin (an epithelial marker) was examined in cytoplasm by scanning confocal
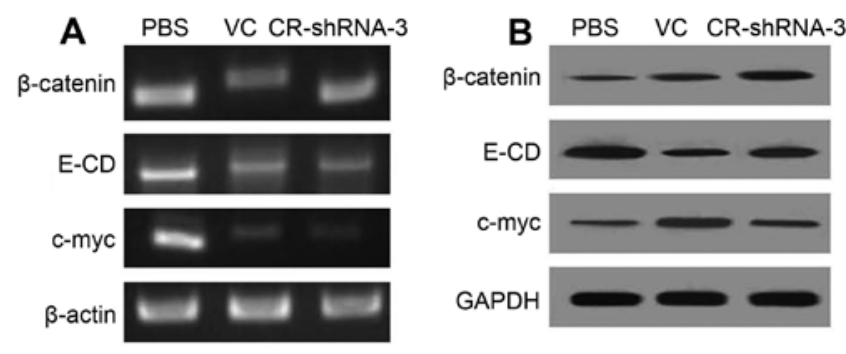

PC-3

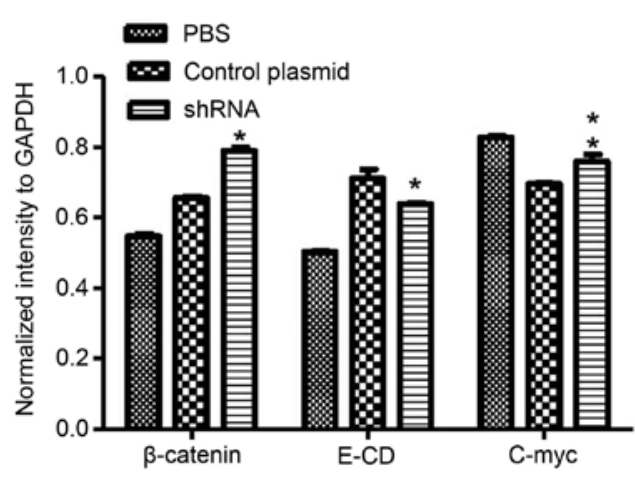

Figure 5. Silencing of CR-1 reverses the EMT phenotype in PC-3 cells. (A) CR-1 silencing of PC-3 cells were EMT-relative at mRNA levels. ( $\beta$-actin, internal reference). (B) CR-1 silencing PC-3 cells were EMT-relative proteins. (GAPDH, internal reference) $\left({ }^{*} \mathrm{P}<0.01\right.$ and $\left.{ }^{* *} \mathrm{P}<0.05\right)$.

microscopy (Fig. 4B). $\beta$-catenin was prominently expressed at low level throughout the cytoplasm of PC-3 cells; whereas, a significantly enhanced E-CD was detected. Expression of CR-1 and EMT markers in PC-3 prompted us to examine whether CR-1 silencing could be in lost in mesenchymal and gained in epithelial markers. To further determine if this transformation represented an EMT, RT-PCR and western blotting were used to show the relationship between CR-1 and EMT. We found that c-myc was markedly decreased by stable transfection with CR-1-shRNA-3. In addition, $\beta$-catenin levels were increased in the membrane, while E-cadherin expression levels were also higher in PC-3 CR-1-shRNA-3 cells (Fig. 5). Thus, our data demonstrated that CR-1 likely plays a crucial part in mediating the EMT in PC-3 cells.

Identification of the characteristic protein and signal pathways associated with EMT in CR-1 silencing PC-3 cells after adding Licl. MTT assay demonstrated that after the treatment with different concentrations of Licl, proliferation of PC-3 cell was significantly decreased and cells appeared shrunken and non-viable. Inhibiting effect of Licl was dose-dependent (Fig. 3). We adopted $40 \mathrm{mmol} / \mathrm{l}$ of Licl for $48 \mathrm{~h}$ to inhibit the tumor growth of PC-3 by Wnt/ $\beta$-catenin pathway. To explore which pathways were activated during EMT mediated by CR-1, we adopted 5 differentially expressed genes regulated by CR-1 silencing in PC-3 cells after adding Licl. As shown in Fig. 6 we also especially focused on the relationship between CR-1 and Wnt/ $\beta$-catenin pathway. Licl (Wnt/ $\beta$-catenin pathway inhibitors) was pretreated in CR-1 silenced PC-3. Licl upregulated E-cadherin, $\beta$-catenin and p-GSK-3 $\beta$ in CR-1 silenced PC-3 cell lines. In accordance with mRNA, western blotting revealed that the effects of CR-1 on enhancing EMT phenotype were eliminated in Licl pretreated groups. GSK-3 $\beta$ 

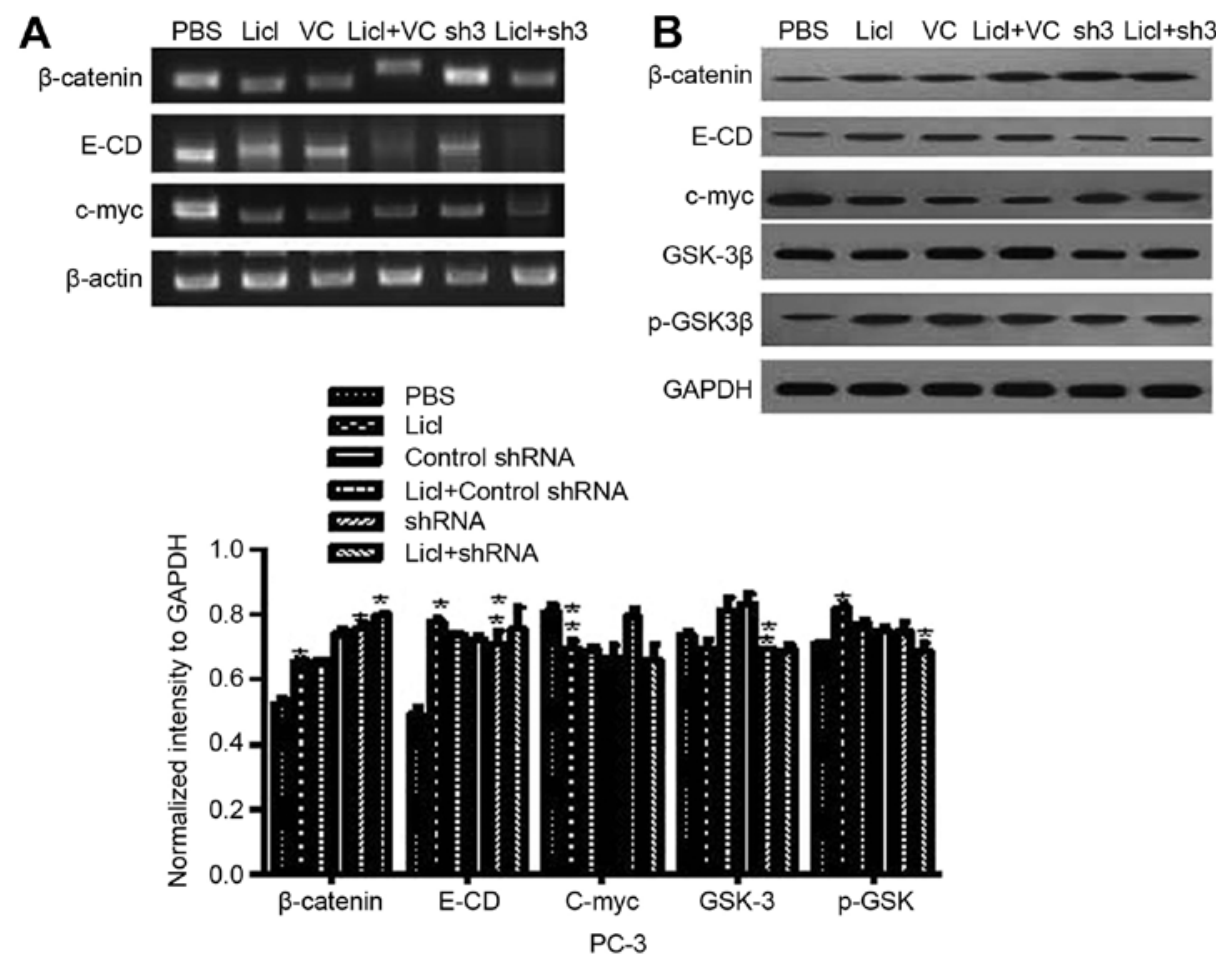

Figure 6. Impact of Licl on the cell EMT phenotype in CR-1 silencing PC-3 cells. (A) After adding Licl, gene expression of relative EMT in CR-1 silencing PC-3. ( $\beta$-actin, internal reference). (B) After adding Licl, relative EMT proteins in CR-1 silencing PC-3. (GAPDH, internal reference) $\left({ }^{*} \mathrm{P}<0.01 ;{ }^{* *} \mathrm{P}<0.05\right)$.

A
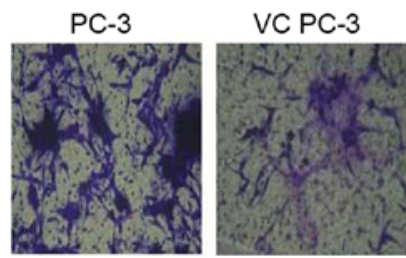

B

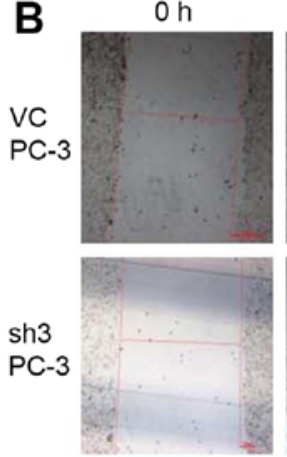

$12 \mathrm{~h}$
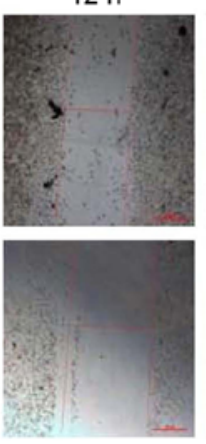

sh3-PC-3

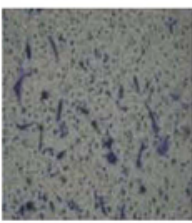

$24 \mathrm{~h}$

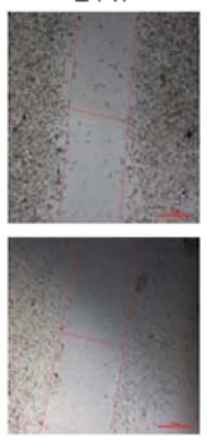

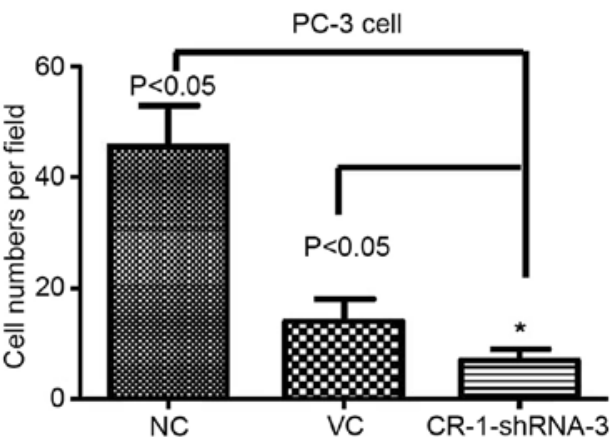

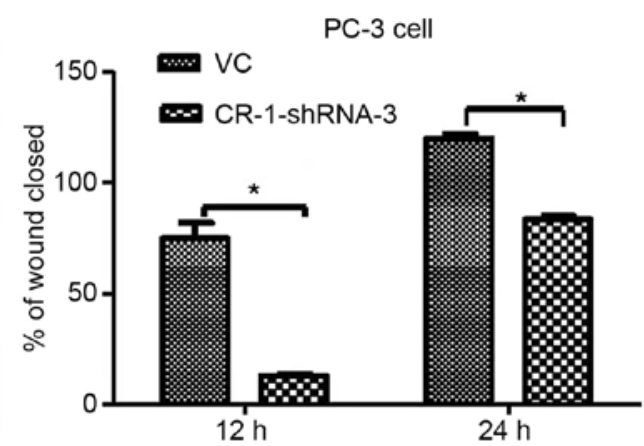

Figure 7. CR-1 actively regulating the invasiveness of PCa. (A) Transwell assay showing cell invasion in PC-3 cells (magnification, $\mathrm{x} 200$ ). (B) Wound healing assay showing cell migration (magnification, $\mathrm{x} 40)\left({ }^{*} \mathrm{P}<0.05\right)$.

and c-myc were downregulated (Fig. 6). We demonstrated that CR-1 acted by Wnt/ß-catenin pathway inducing EMT.

To investigate the invasion effects of silencing CR-1 in PC-3. CR-1 silencing (CR-1-shRNA-3) and vector control (VC) cells from PC-3 were established. Transwell assay revealed that silencing CR-1 strongly suppressed the invasive ability in PC-3 compared to non-transfected PC-3 or CR-1-VC-shRNA-3 cells (both $\mathrm{P}<0.05$ ) (Fig. 7A). High expression of CR-1 was proved to strengthen invasiveness in PC-3 cells. In addition, wound 
healing assay showed that silencing CR-1 decreased healing speed of the scratch in transfected cells. Wound closure rate of CR-1-shRNA-3-PC3 cells was significantly less than that of non-transfected PC-3 cells and CR-1-VC-shRNA-3-PC3 cells (both $\mathrm{P}<0.05$ ). No obvious differences in the wound closure rates between CR-1-VC-shRNA-3-PC3 cells and non-transfected PC-3 cells were detected (Fig. 7B). Collectively, these data indicated that CR-1 stimulated PCa cell invasiveness.

\section{Discussion}

In the present study, high expression levels of CR-1 were observed in $\mathrm{PCa}$ which is consistent with previous studies. Reports illustrated that CR-1 upregulated due to the EGF-CFC family members $(4,17)$. Gene expressions have shown an important role of CR-1 by Wnt/ $\beta$-catenin pathway in PCa cells. CR-1 positively regulated proliferation, invasion and migration leading to EMT. These findings provided strong evidence that elevated CR-1 promotes metastatic ability, EMT and stages of tumor progression via Wnt/ $\beta$-catenin pathway in $\mathrm{PC}-3$, which further supported that CR-1 could be a therapeutic target in PCa.

Since the role of CR-1 promotes tumor progression via signaling pathway in tumor cells, some studies have focused on CR-1 in colon, breast, gastric cancer, hepatocellular carcinoma, pancreatic and bladder cancer (12,18-20). It was found that CR-1 stimulated cell proliferation and EMT (21). Bianco et al (22) showed that CR-1 activated the ras/raf/MAPK pathway and suppressed epithelial cells. Shukla et al (23) reported that CR-1 was overexpressed in mouse skin carcinogenesis. Xu et al (24) found that the serum CR-1 levels were extremely high in lung cancer patients. Another study also found the same conclusion (11). Here, IHC showed that CR-1 expressed mainly in PCa cytoplasm, which was in accordance with the report of Gong et al in breast cancer (25). Furthermore, CR-1 had a positive correlation with the patient PSA level, Gleason, clinical stage and lymph node metastasis.

A correlation between CR-1 and EMT marker was also found in $\mathrm{PCa}$. In the EMT process, downregulation of E-cadherin can cause cellular changes in different aspects $(26,27)$. Our present findings indicated that CR-1 silencing resulted in marked changes in the reduction of mesenchymal proteins and the appearance of epithelial proteins. E-cadherin levels increased in CR-1 silenced PC-3 cells with a concomitant increase in $\beta$-catenin expression in membranes. In part, CR-1 could regulate EMT by activating Wnt $/ \beta$-catenin pathway in PC-3 cells. We found that silencing of CR-1 led to $\beta$-catenin c-myc and GSK-3 $\beta$ downregulation. Zhong et al (28) indicated that overexpressed CR-1 led to lower expression of E-CD in gastric cancer patients. CR-1 and E-cadherin show potential to become valuable markers for diagnosing and monitoring of gastric cancer. Similarly, activated CR-1 induced EMT in HC-11 and Eph4 cells, in which E-cadherin was downregulated (29). The accumulated data strongly suggested that silencing of CR-1 might regulate the process of EMT through downregulation of GSK-3 $\beta$ to activation of E-cadherin. This agrees with Strizzi et al (9) who demonstrated that CR-1 was well correlated with EMT marker proteins.
In the present study, we found that after adding Licl, proliferation of PC-3 cells was decreased. Cell inhibition rates were time- and concentration-dependent. Hou et al (30) also reported that Licl disrupted DNA replication and suppressed PCa cell growth, which was in accordance with our research. Furthermore, some other evidence reported that Licl was a direct inhibitor of GSK-3 $\beta$ which induced GSK-3 $\beta$ N-terminal phosphorylation (31). Licl was used to pretreat CR-1 silencing PC-3 cells. Our results found that the levels of GSK-3 $\beta$ and c-myc were substantially inhibited by CR-1 silencing after adding Licl, whereas, it increased the levels of $\beta$-catenin, p-GSK-3 $\beta$ and E-CD by means of Wnt/ $\beta$-catenin pathway, compared with the IF control groups. Our data suggested that CR-1 activated by Wnt/ $\beta$-catenin induced EMT in PC-3.

In addition, we applied the Transwell assay to observe cell invasiveness after CR-1 silencing. Silencing CR-1 by shRNA interference attenuates the CR-1-stimulation-induced migration and invasion. Results from cells in vitro invasion indicated that the number of cells that penetrated the basal membrane from silenced CR-1 group was significantly less than vector control group. Loss of CR-1 suppressed invasion of PCa cells. After downregulation of CR-1 expression, the cell invasive ability and proliferation rate in PC-3 cells was significantly decreased. Similarly, Huang and colleagues (32) reported that CR-1 interference significantly reduced the migratory activity of cells, suggesting that CR-1 enhanced cell invasiveness in esophageal squamous cell carcinoma. Wu et al (33) also reported the same conclusion in nasopharyngeal carcinoma. In brief, CR-1 stimulated PCa cell invasiveness via the activation of $\mathrm{Wnt} / \beta$-catenin pathway.

Our key finding is that activated CR-1 can increase the proliferation and invasion of PCa cells. Levels of EMT relative proteins were changed in CR-1 silenced PC-3 when Wnt/ $\beta$-catenin signaling pathway was activated. This result indicated that CR-1 activated Wnt/ $\beta$-catenin signaling pathway and promoted the occurrence of EMT in PCa. CR-1 may serve as a new biological marker for clinical treatment against $\mathrm{PCa}$.

\section{Acknowledgements}

The present study was supported by grants (81472416) from the National Natural Science Foundation of China and grants (20140122) from the Tianjin Municipal Education Commission.

\section{References}

1. Siegel RL, Miller KD and Jemal A: Cancer statistics, 2016. CA Cancer J Clin 66: 7-30, 2016.

2. Center MM, Jemal A, Lortet-Tieulent J, Ward E, Ferlay J, Brawley $\mathrm{O}$ and Bray $\mathrm{F}$ : International variation in prostate cancer incidence and mortality rates. Eur Urol 61: 1079-1092, 2012.

3. Attard G,Parker C, Eeles RA, Schröder F, Tomlins SA, Tannock I, Drake CG and de Bono JS: Prostate cancer. Lancet 387: 70-82, 2016.

4. Saloman DS, Bianco C, Ebert AD, Khan NI, De Santis M, Normanno N, Wechselberger C, Seno M, Williams K, Sanicola M, et al: The EGF-CFC family: Novel epidermal growth factor-related proteins in development and cancer. Endocr Relat Cancer 7: 199-226, 2000

5. Ciccodicola A, Dono R, Obici S, Simeone A, Zollo M and Persico MG: Molecular characterization of a gene of the 'EGF family' expressed in undifferentiated human NTERA2 teratocarcinoma cells. EMBO J 8: 1987-1991, 1989. 
6. Bianco C, Rangel MC, Castro NP, Nagaoka T, Rollman K, Gonzales $\mathrm{M}$ and Salomon DS: Role of Cripto-1 in stem cell maintenance and malignant progression. Am J Pathol 177: 532-540, 2010

7. Bianco C, Strizzi L, Normanno N, Khan N and Salomon DS: Cripto-1: An oncofetal gene with many faces. Curr Top Dev Biol 67: 85-133, 2005.

8. de Castro NP, Rangel MC, Nagaoka T, Salomon DS and Bianco C: Cripto-1: An embryonic gene that promotes tumorigenesis. Future Oncol 6: 1127-1142, 2010.

9. Strizzi L, Bianco C, Normanno N, Seno M, Wechselberger C, Wallace-Jones B, Khan NI, Hirota M, Sun Y, Sanicola M, et al: Epithelial mesenchymal transition is a characteristic of hyperplasias and tumors in mammary gland from MMTV-Cripto-1 transgenic mice. J Cell Physiol 201: 266-276, 2004.

10. Wechselberger C, Ebert AD, Bianco C, Khan NI, Sun Y, Wallace-Jones B, Montesano R and Salomon DS: Cripto-1 enhances migration and branching morphogenesis of mouse mammary epithelial cells. Exp Cell Res 266: 95-105, 2001

11. Wechselberger C, Strizzi L, Kenney N, Hirota M, Sun Y Ebert A, Orozco O, Bianco C, Khan NI, Wallace-Jones B, et al: Human Cripto-1 overexpression in the mouse mammary gland results in the development of hyperplasia and adenocarcinoma. Oncogene 24: 4094-4105, 2005.

12. Strizzi L, Bianco C, Normanno N and Salomon D: Cripto-1: A multifunctional modulator during embryogenesis and oncogenesis. Oncogene 24: 5731-5741, 2005.

13. Rangel MC, Karasawa H, Castro NP, Nagaoka T, Salomon DS and Bianco C: Role of Cripto-1 during epithelial-to-mesenchymal transition in development and cancer. Am J Pathol 180: 2188-2200, 2012.

14. Acloque H, Adams MS, Fishwick K, Bronner-Fraser M and Nieto MA: Epithelial-mesenchymal transitions: The importance of changing cell state in development and disease. J Clin Invest 119: 1438-1449, 2009.

15. Prasad CP, Rath G, Mathur S, Bhatnagar D, Parshad R and Ralhan R: Expression analysis of E-cadherin, Slug and GSK3beta in invasive ductal carcinoma of breast. BMC Cancer 9: 325 , 2009.

16. Li Y, Che Q, Bian Y, Zhou Q, Jiang F, Tong H, Ke J, Wang K and Wan XP: Autocrine motility factor promotes epithelial-mesenchymal transition in endometrial cancer via MAPK signaling pathway. Int J Oncol 47: 1017-1024, 2015.

17. Adamson ED, Minchiotti G and Salomon DS: Cripto: A tumor growth factor and more. J Cell Physiol 190: 267-278, 2002.

18. Bianco C, Normanno N, De Luca A, Maiello MR, Wechselberger C, Sun Y, Khan N, Adkins H, Sanicola M, Vonderhaar B, et al: Detection and localization of Cripto-1 binding in mouse mammary epithelial cells and in the mouse mammary gland using an immunoglobulin-cripto-1 fusion protein. J Cell Physiol 190: 74-82, 2002.

19. Wei B, Jin W, Ruan J, Xu Z, Zhou Y, Liang J, Cheng H, Jin K, Huang X, Lu P, et al: Cripto-1 expression and its prognostic value in human bladder cancer patients. Tumour Biol 36: 1105-1113, 2015 .
20. Wang JH, Wei W, Xu J, Guo ZX, Xiao CZ, Zhang YF, Jian PE, Wu XL, Shi M and Guo RP: Elevated expression of Cripto-1 correlates with poor prognosis in hepatocellular carcinoma. Oncotarget 6: 35116-35128, 2015.

21. Nagaoka T, Karasawa H, Castro NP, Rangel MC, Salomon DS and Bianco C: An evolving web of signaling networks regulated by Cripto-1. Growth Factors 30: 13-21, 2012.

22. Bianco C, Castro NP, Baraty C, Rollman K, Held N, Rangel MC, Karasawa H, Gonzales M, Strizzi L and Salomon DS: Regulation of human Cripto-1 expression by nuclear receptors and DNA promoter methylation in human embryonal and breast cancer cells. J Cell Physiol 228: 1174-1188, 2013.

23. Shukla A, Ho Y, Liu X, Ryscavage A and Glick AB: Cripto-1 alters keratinocyte differentiation via blockade of transforming growth factor-beta1 signaling: Role in skin carcinogenesis. Mol Cancer Res 6: 509-516, 2008.

24. Xu CH, Wang Y, Qian LH, Yu LK, Zhang XW and Wang QB: Serum Cripto-1 is a novel biomarker for non-small cell lung cancer diagnosis and prognosis. Clin Respir J: Nov 25, 2015 (Epub ahead of print) doi: 10.1111/crj.12414.

25. Gong YP, Yarrow PM, Carmalt HL, Kwun SY, Kennedy CW, Lin BP, Xing PX and Gillett DJ: Overexpression of Cripto and its prognostic significance in breast cancer: A study with long-term survival. Eur J Surg Oncol 33: 438-443, 2007.

26. Yang J and Weinberg RA: Epithelial-mesenchymal transition: At the crossroads of development and tumor metastasis. Dev Cell 14: 818-829, 2008.

27. Klauzinska M, Castro NP, Rangel MC, Spike BT, Gray PC, Bertolette D, Cuttitta F and Salomon D: The multifaceted role of the embryonic gene Cripto-1 in cancer, stem cells and epithelialmesenchymal transition. Semin Cancer Biol 29: 51-58, 2014.

28. Zhong XY, Zhang LH, Jia SQ, Shi T, Niu ZJ, Du H, Zhang GG, $\mathrm{Hu}$ Y, Lu AP, Li JY, et al: Positive association of up-regulated Cripto-1 and down-regulated E-cadherin with tumour progression and poor prognosis in gastric cancer. Histopathology 52: 560-568, 2008.

29. Strizzi L, Bianco C, Raafat A, Abdallah W, Chang C, Raafat D, Hirota M, Hamada S, Sun Y, Normanno N, et al: Netrin-1 regulates invasion and migration of mouse mammary epithelial cells overexpressing Cripto-1 in vitro and in vivo. J Cell Sci 118 : 4633-4643, 2005.

30. Hou CL, Zhang ZH, Huang DL and Sun AJ: LiCl suppresses tumor growth and inhibits DNA replication in prostate cancer. Zhonghua Bing Li Xue Za Zhi 41: 475-478, 2012 (In Chinese).

31. Zhang F, Phiel CJ, Spece L, Gurvich N and Klein PS: Inhibitory phosphorylation of glycogen synthase kinase-3 (GSK-3) in response to lithium. Evidence for autoregulation of GSK-3. J Biol Chem 278: 33067-33077, 2003.

32. Huang C, Chen W, Wang X, Zhao J, Li Q and Fu Z: Cripto-1 promotes the epithelial-mesenchymal transition in esophageal squamous cell carcinoma cells. Evid Based Complement Alternat Med 2015: 421285, 2015.

33. Wu Z, Li G, Wu L, Weng D, Li X and Yao K: Cripto-1 overexpression is involved in the tumorigenesis of nasopharyngeal carcinoma. BMC Cancer 9: 315, 2009. 